\title{
A FORMAÇÃO DO PROFESSOR DE SOCIOLOGIA DO ENSINO MÉDIO: UM ESTUDO SOBRE O CURSO DE CIÊNCIAS SOCIAIS DA UNIVERSIDADE DE SÃO PAULO
}

\section{THE FORMATION OF THE HIGH SCHOOL SOCIOLOGY TEACHER: A STUDY OF THE SOCIAL SCIENCIES OF THE UNIVERSITY OF SÃO PAULO}

\author{
Cassiana Tiemi Tedesco Takagi ${ }^{1}$
}

\section{RESUMO}

Este trabalho analisa os cursos de bacharelado e licenciatura em Ciências Sociais da Universidade de São Paulo desde a sua fundação até os dias atuais. Considerouse que o curso de licenciatura da USP, por ser o mais longevo e de certa forma inaugural, seria capaz de fornecer, a partir de seus arquivos, os subsídios necessários para se compreender a formação docente.

Palavras-chave: Curso de licenciatura. Ensino de Sociologia. Universidade de São Paulo. Educação.

\begin{abstract}
This work analyses the courses of bachelor's degree and licentiate's degree in Social Sciences at the University of São Paulo, since its foundation to the present days. It was considered that the licentiate course of USP, which is the most long lasting and in some way inaugural, would be able to provide, from its archives, the subsidies that are necessary to the comprehension of teacher education formation.
\end{abstract}

Key-words: Licentiate course. Teaching of Sociology. University of São Paulo. Education.

\section{CLASSES SOCIAIS E SUAS INFLUÊNCIAS}

\footnotetext{
${ }^{1}$ Graduada em Ciências Sociais (2000) e em Pedagogia (2004) pela Universidade de São Paulo. Mestre em Educação (2007) e doutora em Educação (2013) pela Universidade de São Paulo.
} 
A FORMAÇÃO DO PROFESSOR DE SOCIOLOGIA DO ENSINO MÉDIO: UM ESTUDO SOBRE O CURSO DE CIÊNCIAS SOCIAIS DA UNIVERSIDADE DE SÃO PAULO Cassiana Tiemi Tedesco Takagi

As discussões sobre a formação docente usualmente debatem o seguinte:

\begin{abstract}
A formação inicial é considerada "demasiadamente teórica" ou "não suficientemente prática", "muito afastada da realidade de sala de aula" ou "demasiadamente ligada a modelos". Os professores queixam-se que seus formadores "não explicam o suficiente" sobre as dificuldades que seriam encontradas, nem da influência dos problemas sociais sobre a classe: que não "forneceram informações suficientes" sobre a psicologia do aluno, as técnicas, etc. Acusamnos ainda de haverem "infantilizado" o ofício (Louvet e Baillauquès, 1992). Por outro lado, eles mesmos são taxados de resistentes à mudança e ao autoquestionamento, de pouco participantes e de conformistas, quando não de apresentarem comportamento infantil; de rejeitarem qualquer teorização e de esperarem de maneira primária por receitas prontas... receitas estas que os formadores evitarão fornecer (BAILLAUQUÉS, 2001, p. 47).
\end{abstract}

Esse embate entre o teórico e o prático nas formações docentes é bastante recorrente, porém, pouco se avança nessa questão em termos "práticos", porque, por um lado, a linguagem acadêmica não atinge o docente, que olha para sua prática e afirma que "os formadores não explicam o suficiente", por outro lado, os docentes da educação básica são taxados de resistentes. Sendo assim, o foco da questão não é a diferença entre teoria e prática, mas a formação, porque

Boa parte desses professores aprendeu seu ofício como os antigos aprendiam: fazendo. Os professores universitários não recebem preparação pedagógica específica e mesmo ao longo da sua vida profissional raramente têm a oportunidade de participar em cursos, seminários ou reuniões sobre métodos de ensino e avaliação da aprendizagem. A pedagogia fica, portanto, ao sabor dos dotes naturais da cada professor (GIL, 2012, p. 8-9).

Por esse motivo, mantém-se na formação inicial o mesmo ideário de acumulação de conhecimentos e ausência de necessidade de algum tipo de preparação pedagógica:

As dificuldades simbólicas lidam diretamente com a inserção acadêmica em termos de novas tarefas a serem feitas: seminários, trabalhos científicos, leitura de textos acadêmicos e textos em línguas estrangeiras, além de contato com teorias. Conforme delineada acima, a entrada no ambiente universitário é marcada por

Inter-Legere - Revista de Pós Graduação em Ciências Sociais da UFRN

Natal RN, ISSN 1982-1662 no 18, jan./jun. de 2016 p. 150-167 
uma ruptura em relação aos graus anteriores de escolaridade: na universidade, o aluno torna-se o principal ator de sua vida escolar. [...] Se todos "se viram" para conseguir efetuar as tarefas solicitadas, há vivências diferentes: os que defendem a existência de auxílios na grade curricular, outros que concordam com o ritmo imposto, porém, entendem que se deve buscar um "meio termo", pois nem todos estão suficientemente preparados para suportar as exigências solicitadas e, por fim, aqueles que destacam esse trabalho independente exigido como diferencial da USP perante outras instituições, "forçando" o aluno a buscar conhecimento e, desse modo, possibilitando a ele um desenvolvimento intelectual (ALMEIDA, 2009, p. 135).

Quando Almeida (2009) analisa o ingresso dos estudantes nos cursos universitários, ele caracteriza esse momento como de ruptura, porque o aluno deixa de ser tutelado e se torna autônomo. No entanto, o processo de autonomia educacional exige disposições presentes no "capital cultural" (BOURDIEU apud CATANI; NOGUEIRA, 2008) para atender ao grau de exigência do curso da USP, conforme Almeida salienta, porém, essa exigência não é caracterizada somente pelo fato de o aluno ser "forçado" a buscar conhecimento, mas também pela maneira como o curso é organizado:

[...] dos docentes universitários costuma-se esperar um conhecimento do campo científico de sua área, alicerçado nos rigores da ciência, e um exercício profissional que legitime esse saber no espaço da prática. Contando com a maturidade dos alunos do ensino superior para responder às exigências da aprendizagem nesse nível e tendo como pressuposto o paradigma tradicional de transmissão do conhecimento, não se registra, historicamente, uma preocupação significativa com os conhecimentos pedagógicos (CUNHA, 2009, p. 213).

O foco do currículo de Ciências Sociais é o conhecimento do campo científico, especialmente quando se analisa o bacharelado. Além disso, Cunha (2009) alerta para a inexistência de preocupação com os conhecimentos pedagógicos, que são encontrados somente na licenciatura. Desse modo, os docentes universitários preocupam-se essencialmente com o conteúdo, vinculando seu aprendizado a um processo de acumulação e esforço por parte do aluno.

Essa concepção não é nova nos cursos da USP, porque os docentes 
A FORMAÇÃO DO PROFESSOR DE SOCIOLOGIA DO ENSINO MÉDIO: UM ESTUDO SOBRE O CURSO DE CIÊNCIAS SOCIAIS DA UNIVERSIDADE DE SÃO PAULO Cassiana Tiemi Tedesco Takagi

aprenderam com seus professores, tornando-se um processo de autorreprodução. Essa concepção se perpetua desde a ação da intelligentsia:

[...] desempenho de uma intelligentsia e seu tipo de ideação [que] dependem das circunstâncias sob as quais [a intelligentsia] se torna reflexiva e articulada. Quer se trate de um grupo deslocado, ascendente ou reprimido em seu movimento ascensional, ela tende a cristalizar as convenções dominantes de sua sociedade. Sua natureza varia de uma cultura para outra, dependendo das vias pelas quais chega a assumir funções-chave na sociedade. [...] quando a intelligentsia assume sua posição, ela estabelece o padrão de erudição para a elite dominante e, através dela, para a sociedade inteira (MANNHEIM, 2012, p. 124).

A influência da intelligentsia marca a definição de classe social desde a formação da USP, embora se reconheça que sua criação seria bastante improvável sem a "autorização" das elites, por envolver custos governamentais consideráveis e um aparato de rede de influências para a obtenção de vários interesses e incrementos institucionais para a Universidade - docentes estrangeiros e financiamento externo. Nesse sentido, como afirma Nunes (2012, p. 209-210),

[...] o modelo de ensino superior público que temos é caro, de boa qualidade, baseado em professores adequadamente titulados e com carreiras corretamente remuneradas, essencialmente em regime de dedicação integral. É, claro, um modelo destinado à formação de elites. E elites custam caro.

A análise de Nunes (2012) tanto se refere ao início da USP quanto ao momento atual, porque a "boa qualidade" do ensino universitário público exige sempre investimentos elevados, tendo em vista que este está "destinado à formação de elites".

Sistema de classificação objetivado em instituições cujas divisões reproduzem sob uma forma irreconhecível a divisão social do trabalho, o sistema de ensino opera classificações que se traduzem primeiramente pela atribuição às classes escolares (classes, seções, etc.) e, em seguida, às classes sociais (BOURDIEU apud CATANI; NOGUEIRA, 2008, p. 198). 
A FORMAÇÃO DO PROFESSOR DE SOCIOLOGIA DO ENSINO MÉDIO: UM ESTUDO SOBRE O CURSO DE CIÊNCIAS SOCIAIS DA UNIVERSIDADE DE SÃO PAULO Cassiana Tiemi Tedesco Takagi

Para Bourdieu (apud CATANI; NOGUEIRA, 2008), "o sistema de ensino opera classificações que se traduzem [...] pela atribuição [...] às classes sociais". Nesse sentido, a instituição escolar está contaminada pela divisão social.

Desse modo, o estudo do currículo revela as relações de poder:

[...] o conhecimento curricular não é um "dado", mas, antes, o resultado da luta social decorrente da distribuição desigual da riqueza e do poder. É útil perspectivar os currículos enquanto justificações ideológicas das relações de classe. Para além disso, eles podem ser conceitualizados num sentido mais estrito (como conhecimento da sala de aula) ou mais global (enquanto somatório total resultante da exposição de um aluno à ideologia de uma escola) (GOODSON, 2001, p. 196).

O currículo da USP revela essa distribuição desigual de riqueza e poder, especialmente no início dos cursos, quando estes eram dirigidos exclusivamente às elites e a universidade se prestava ao incremento intelectual dessa classe social.

A criança não interioriza o mundo dos outros que são significativos para ela como sendo um dos muitos mundos possíveis. Interioriza-se como sendo o mundo, o único mundo existente e concebível, o mundo tout court. É por esta razão que o mundo interiorizado na socialização primária torna-se muito mais firmemente entrincheirado na consciência do que os mundos interiorizados nas socializações secundárias (BERGER; LUCKMANN, 2012, p. 174).

Para os autores, a construção da identidade desde a infância é dada em um contexto social específico, assim, a criança da elite interioriza as proposições sociais "como sendo o mundo, o único mundo existente e cabível" na socialização primária. Nesse momento, ela se desenvolve em um contexto repleto de valores da elite, enquanto a criança de classe trabalhadora, embora seja socializada sob as prerrogativas da socialização primária e tenda a agir conforme seu contexto social, dificilmente se desenvolve isoladamente e por isso pode tomar conhecimento da existência de outros mundos, mesmo se reconhecendo como não pertencente. $\mathrm{A}$ criança da elite, ao contrário, pode ser criada em certo isolamento, o que torna possível que ela desconheça outras realidades sociais. Nesse contexto, ela é cerceada de uma série de possibilidades de apreensão de conhecimentos - livros,

Inter-Legere - Revista de Pós Graduação em Ciências Sociais da UFRN Natal RN, ISSN 1982-1662 no 18, jan./jun. de 2016 p. 150-167 
A FORMAÇÃO DO PROFESSOR DE SOCIOLOGIA DO ENSINO MÉDIO: UM ESTUDO SOBRE O CURSO DE CIÊNCIAS SOCIAIS DA UNIVERSIDADE DE SÃO PAULO Cassiana Tiemi Tedesco Takagi

música e demais recursos artísticos -, ao mesmo tempo que é "protegida" do convívio com os demais grupos sociais, inclusive no ambiente escolar.

Obviamente que estas escolas não produzem estes resultados "sozinhas". Pelo contrário, é a interação complexa entre as famílias e as organizações escolares que reforça o papel poderoso de certas organizações familiares e classes sociais. A maior parte das investigações realizadas sobre estas escolas focou o status social dos seus corpos discentes e as ligações que estas instituições estabelecem com colleges seletivos e, através destes, com empregadores e redes sociais altamente prestigiadas (GOODSON, 2001, p. 199).

A família desempenha um importante papel na socialização primária e usualmente as crianças da elite ficam imersas no mesmo contexto social ao longo de sua escolaridade. Nesse sentido, as organizações escolares reforçam o papel das organizações familiares e o das classes sociais ao incutirem normas e modos de agir no indivíduo que são respostas enquadradas no contexto social da elite e estão tão inerentes que ele sente que são individuais, mesmo sendo produto das normas sociais de sua classe social.

[...] a norma generaliza-se tomando a expressão "Não se deve derramar a sopa", sendo o "se" parte de uma generalidade que inclui, em princípio, toda a sociedade, na medida em que é significativa para a criança. Esta abstração dos papéis e atitudes dos outros significativos concretos é chamada o outro generalizado. Sua formação na consciência significa que o indivíduo identifica-se agora não somente com os outros concretos, mas com uma generalidade de outros, isto é, com uma sociedade. Somente em virtude desta identificação generalidade sua identificação consigo mesmo alcança estabilidade e continuidade (BERGER; LUCKMANN, 2012, p. 172).

A norma é construída no indivíduo por meio de orientações externas que, ao longo do tempo, são introjetadas, porque "o indivíduo identifica-se agora não somente com os outros concretos, mas com uma generalidade de outros". Por essa razão, a criança passa a oferecer respostas "típicas" de sua origem social, seguindo as normas de seu grupo.

Dados desta pesquisa sugerem que tornar-se usuário da cultura

Inter-Legere - Revista de Pós Graduação em Ciências Sociais da UFRN

Natal RN, ISSN 1982-1662 no 18, jan./jun. de 2016 p. 150-167 
escrita, ou ao menos, dela estar mais familiarizado, representa um elemento identitário importante na construção dessa sociabilidade. Percebe-se, também, que, para atravessar essa "roleta", é preciso conhecer e dominar um complexo jogo de códigos, que nada tem de natural. É preciso ser um igual, é preciso renunciar aos conteúdos objetivos e subjetivos de sua cultura de origem, experiência relatada pelos entrevistados oriundos das camadas populares como de bastante angústia (PAVÃO, 2007, p. 83).

Esses elementos se constituem não somente para a formação do indivíduo pertencente a uma sociedade, mas também para um processo identitário de cultura universitária. O "complexo jogo de códigos" foi construído em contextos culturais específicos, porque "é preciso ser um igual, é preciso renunciar aos conteúdos objetivos e subjetivos de uma cultura de origem". Em uma instituição universitária, esse processo de abandono da cultura de origem nem sempre é fácil ou evidente, porque os alunos de camadas populares demoram muito para entender - assumir as normas institucionais, que pouco se relacionam com seu grupo social de origem.

No caso em que o discurso filosófico se reduz ao que frequentemente se oferece nas classes de filosofia sob o nome de moral ou psicologia, quer dizer, uma variante universitária do discurso dominante sobre o mundo social, a harmonia é quase perfeita entre a estrutura de discurso transmitido e as estruturas de percepção e apreciação que o campo universitário impõe, tanto aos emissores quanto aos receptores desse discurso (BOURDIEU apud CATANI; NOGUEIRA, 2008, p. 200).

O discurso dominante sobre o mundo é construído em um processo harmônico quase perfeito, no qual emissores e receptores são participantes do discurso e, por isso, o compartilham.

Com base em sua pesquisa etnográfica em escolas, Gloria Landson Billings (1994) sugere que o ensino de qualidade não ocorre quando os estudantes precisam abandonar suas identidades culturais para aprender, mas quando os educadores consideram a cultura dos alunos como um recurso, em vez de um impedimento. Ela descobriu que os professores bem-sucedidos de estudantes afro-americanos consideravam "ensinar como 'desenterrar o conhecimento' dos estudantes" e tinham "uma crença esmagadora de que os estudantes vinham para a escola com conhecimento e de que esse conhecimento devia ser explorado e utilizado" (p. 52) (BURAS; 
A FORMAÇÃO DO PROFESSOR DE SOCIOLOGIA DO ENSINO MÉDIO: UM ESTUDO SOBRE O CURSO DE CIÊNCIAS SOCIAIS DA UNIVERSIDADE DE SÃO PAULO Cassiana Tiemi Tedesco Takagi

APPLE, 2008, p. 54-55).

Embora Bourdieu (apud CATANI; NOGUEIRA, 2008) faça um alerta sobre o compartilhamento do discurso, Buras e Apple (2008) analisam uma pesquisa que discorre sobre a importância da identidade cultural do aluno no aprendizado, porque os professores usaram a cultura dos alunos como recurso. Entretanto, isso não foi observado no curso de Ciências Sociais.

[...] embora a escolarização obrigatória tenha alterado diversos aspectos da infância ela não produziu resultados homogêneos que pudessem ser generalizados para todos os setores sociais. De um lado, temos os filhos das elites econômicas e de parte das classes médias, que ingressam tardiamente no mercado de trabalho e que ocupam o seu tempo com diversas atividades, muitas das quais ligadas em termos muito amplos à educação e formação. De outro, temos os filhos das classes populares que, embora frequentem hoje a escola, realizam no restante do dia diversas atividades econômicas mais ou menos informais (CORDEIRO, 2012, p. 76).

Ao se discutir o ensino superior, verifica-se que as condições sociais ausência de "capital cultural" (BOURDIEU apud CATANI; NOGUEIRA, 2008) para acompanhar os cursos - dos estudantes não são identificadas apenas nesse nível educacional, porque a escolarização obrigatória não produziu resultados homogêneos por lidar com questões tanto internas quanto externas. As necessidades de subsistência são imperiosas, obrigando os alunos das classes trabalhadoras a coordenarem o estudo com o trabalho, diferentemente do que ocorre com os membros da elite, que se dedicam exclusivamente aos estudos. Ao longo do percurso educacional, as diferenças vão se agravando, pois as exigências educacionais vão se complexificando e os alunos mais pobres ficam cada vez mais defasados.

No estudo de Almeida (2009), a defasagem dos alunos pobres é revelada tanto nas falas destes quanto nas análises das temáticas discutidas nos grupos focais: "Lúcia e Clara utilizam o artifício de diminuir a quantidade de disciplinas, porém, em contrapartida, com o ônus de ter que alongar a duração de seus cursos" (p. 134); "A cobrança sempre [é] reiterada na sala de aula e, por isso, fonte de 
A FORMAÇÃO DO PROFESSOR DE SOCIOLOGIA DO ENSINO MÉDIO: UM ESTUDO SOBRE O CURSO DE CIÊNCIAS SOCIAIS DA UNIVERSIDADE DE SÃO PAULO

Cassiana Tiemi Tedesco Takagi

constrangimentos para aqueles que não estão à altura para corresponder" (p. 144). Dessa forma, Almeida (2009) aponta o modo como os alunos pobres adaptam-se às exigências de seus cursos e à situação constrangedora que enfrentam em decorrência de suas dificuldades. Bourdieu (apud CATANI; NOGUEIRA, 2008) analisa que essas questões podem fazer parte do próprio sistema escolar, envolvendo indivíduos, mas se constituindo enquanto problema social:

Assim, o sistema escolar pode, por sua lógica própria, servir à perpetuação dos privilégios culturais sem que os privilegiados tenham de se servir dele. Conferindo às desigualdades culturais uma sanção formalmente conforme aos ideais democráticos, ele fornece a melhor justificativa para essas desigualdades (BOURDIEU apud CATANI; NOGUEIRA, 2008, p. 59).

Para além das questões externas, Bourdieu analisa que o sistema escolar serve à perpetuação dos privilegiados ao produzir explicações para as desigualdades e não enfrentar suas questões diretamente.

Supõe-se que os estudantes das escolas privadas despendam uma hora por disciplina para realizarem o trabalho de casa, por noite. Setenta e três por cento dos alunos das escolas públicas afirmam despender cinco horas ou menos por semana, para realizarem os trabalhos de casa, enquanto que $82 \%$ dos das escolas privadas despendem dez ou mais horas por semana; durante o mesmo período $26 \%$ destes referem que gastam mais de vinte horas por semana nos seus trabalhos em casa. Muitos deles inscrevem-se em cursos avançados e poucos, ou mesmo nenhum, veem televisão quando estão na escola (GOODSON, 2001, p. 204).

Goodson (2001) analisa as diferenças entre alunos de escolas privadas e de escolas públicas no que se refere ao tempo de estudo em casa. Ao associar os dados de Goodson (2001) com as análises de Cordeiro (2012), tem-se que os alunos de escolas públicas despendem menos tempo para os estudos em razão de sua atividade econômica, enquanto os alunos das escolas privadas podem se dedicar totalmente aos estudos. Entretanto, os dados de Goodson instrumentalizam a presente discussão por reafirmarem que as elites se distanciam na apreensão do conhecimento de forma bastante rápida, em razão das vantagens internas e 
A FORMAÇÃO DO PROFESSOR DE SOCIOLOGIA DO ENSINO MÉDIO: UM ESTUDO

SOBRE O CURSO DE CIÊNCIAS SOCIAIS DA UNIVERSIDADE DE SÃO PAULO

Cassiana Tiemi Tedesco Takagi

externas ao sistema escolar.

Essas questões explicariam tanto as condições dos alunos ingressantes nas universidades quanto sua permanência no curso, embora pareça, na análise de Goodson, que a questão da defasagem dos alunos de classes populares se daria pela falta de empenho. Bourdieu (apud CATANI; NOGUEIRA, 2008, p. 58) esclarece a questão:

[...] as crianças das classes populares que não empregam na atividade escolar nem a boa vontade cultural das crianças das classes médias nem o capital cultural das classes superiores refugiam-se numa espécie de atitude negativa, que desconcerta educadores e se exprime em formas de desordem até então desconhecidas.

Bourdieu analisa as respostas atitudinais desses alunos, explicando que suas ações negativas - desordem - referem-se ao que lhes resta, pois, por não possuírem o "capital cultural" das elites nem a "boa vontade cultural da classe média", agem assim como grupo excluído que são.

Essa questão remete ao perfil dos estudantes da USP, porque, desde sua fundação, eles foram observados pelos professores estrangeiros:

[...] vinham de longe, esses homens e essas mulheres de todas as idades que se amontoavam em nossas aulas com um fervor desconfiado: jovens de olho nos empregos acessíveis com os diplomas que conferíamos; ou advogados, engenheiros, políticos bem implantados, que temiam a concorrência próxima dos títulos universitários se eles próprios não tivessem o bom senso de disputálos (LÉVI-STRAUSS, 1996, p. 97).

Embora no início os alunos fossem membros da elite, em termos de "capital cultural", eles estavam distantes da expectativa dos docentes estrangeiros, porque, enquanto a intelligentsia primava pelos "altos estudos", grande parte dos estudantes buscava "empregos acessíveis com os diplomas", produzindo um desencontro de expectativas entre docentes e discentes.

Atualmente, a escolha pela USP dos alunos provenientes de classes populares explica-se por outros motivos, para além da excelência do curso e da 
garantia de bons empregos:

\begin{abstract}
Um outro aspecto explorado no decorrer da investigação e que auxilia na caracterização desses estudantes aparece quando da "escolha" da universidade. Em outras palavras, por que a USP nos seus projetos e desejos de vir a ser universitários? Em primeiro plano, antes mesmo do prestígio e distinção dentro do sistema de ensino superior brasileiro, é a gratuidade das universidades públicas que aparece como condição primeira. Assim, conclui-se que, devido às condições financeiras desfavoráveis para suportar um pagamento de um curso superior, a instituição pública de ensino constitui local único no projeto de ser universitário para esses indivíduos [...] (ALMEIDA, 2009, p. 60).
\end{abstract}

Almeida (2009) entrevistou estudantes da USP provenientes de classes baixas e, ao questionar por que decidiram pela USP, eles relataram que a opção por uma instituição pública era a única viável por falta de recursos financeiros. A partir disso, Nunes (2012) explica a faixa etária de estudantes universitários de classes baixas:

[...] a educação superior pública apresenta $11,9 \%$ a mais de alunos na idade adequada do que 0 ensino privado. $O$ setor privado demonstra considerável concentração de alunos com mais de trinta anos, sendo que quase $30 \%$ do total. Isso denota que, enquanto os alunos em idade escolar adequada tendem a ingressar nas instituições públicas, aqueles em idade escolar fora da faixa etária adequada buscam oportunidade de acesso ao ensino superior privado. Ou seja, o ensino superior público tende a ter maior taxa de escolarização líquida que o ensino superior privado. Ainda assim, no total, $45 \%$ dos alunos brasileiros encontram-se na faixa etária acima dos 25 anos (NUNES, 2012, p. 187).

Almeida (2009) entrevistou estudantes de um grupo minoritário na USP, enquanto Nunes (2012) explica que as universidades públicas recebem mais estudantes na idade adequada do que as privadas, sendo estas as que possuem o maior percentual de alunos mais velhos e possivelmente de classes populares. Bourdieu explica que o êxito escolar se relaciona com a origem social:

[...] o sistema de ensino pode acolher um número de educandos cada vez maior - como já ocorreu na primeira metade do século XX - sem ter que se transformar profundamente, desde que os recém- 
A FORMAÇÃO DO PROFESSOR DE SOCIOLOGIA DO ENSINO MÉDIO: UM ESTUDO SOBRE O CURSO DE CIÊNCIAS SOCIAIS DA UNIVERSIDADE DE SÃO PAULO Cassiana Tiemi Tedesco Takagi

chegados sejam também portadores das aptidões socialmente adquiridas que a escola exige tradicionalmente (BOURDIEU apud CATANI; NOGUEIRA, 2008, p. 57).

Além disso, explica que, nos moldes atuais, o sistema de ensino pode abrigar um número cada vez maior de estudantes, desde que eles sejam portadores de "capital cultural" para seguir as exigências educacionais das instituições de ensino.

[...] é importante que as universidades consolidadas com tradição de pesquisa institucionalizada se reorganizem de modo a poderem absorver um contingente muito maior de alunos. Seria possível, por exemplo, instituir o sistema das aulas magnas em que os principais pesquisadores profeririam aulas-conferência para centenas de alunos, sendo o conteúdo aí exposto debatido em seminários menores coordenados por mestrandos, doutorandos ou professores em início de carreira. Cada universidade pública deveria ter constantemente circulando por suas dependências dezenas de milhares de jovens ouvindo aulas-conferência, participando de seminários, frequentando bibliotecas, laboratórios, grupos de pesquisa. O profissional formado nesse ambiente terá uma qualidade sensivelmente diversa daquele formado numa faculdade isolada, tenha ela o nome de "centro universitário" ou mesmo de "universidade", cujo ensino se desenvolva, porém, de forma dissociada dos processos sistemáticos de investigação (SAVIANI, 2001, p. 337).

Saviani (2001) ignora as considerações de Bourdieu (apud CATANI; NOGUEIRA, 2008) ao discorrer sobre a necessidade de ampliação das vagas das universidades, bem como considera que todos os alunos ingressantes são munidos de "capital cultural" e autônomos.

Desse modo, há necessidade de se ter cuidado com a perspectiva de ampliação do curso para um número maior de estudantes. Essa proposta efetiva-se como crítica aos centros universitários, porque neles a "excelência" se dá pelos critérios da elite. Embora não se questione a posição de destaque que as universidades públicas ocupam diante das privadas, é necessário questionar para quem é dirigida tal "excelência".

Se um aluno é capaz de aprender em aulas magnas, pressupõe-se que ele seja autônomo. 
Se não se torna imediatamente um indivíduo dotado de autonomia, ele passa a ser percebido como alguém que caminha no sentido dessa autonomia. Ser aluno, portanto, só pode ser compreendido, a partir dessa noção de transitoriedade, que vai da situação do paciente, daquele que recebe a ação do trabalho institucional e pedagógico da escola, até a situação do agente, aquele que durante o processo da aprendizagem, e com base nele, conquista sua liberdade por meio da aquisição de um conjunto de instrumentos, valores, modos de agir, pensar e se relacionar com o mundo, com a sociedade, com as pessoas (CORDEIRO, 2012, p. 94).

Cordeiro (2012) associa o processo educacional à construção da autonomia, questão que é pertinente, mas deve-se considerar que nem todos os ingressantes na USP apresentam o grau de autonomia necessário. Apesar de eles serem produto de pelo menos onze anos de estudo na educação básica, não é possível garantir que sejam autônomos, nem que possuam o "capital cultural" necessário para acompanhar os cursos universitários.

Nesse sentido, observa-se que a USP, enquanto instituição produtora de normas sociais, cria certos moldes para os seus alunos. Assim, muitas dificuldades vividas por seus estudantes são fruto da necessidade de introjeção de suas normas institucionais, amparada no cultivo dos "altos estudos". Portanto, um aluno que enfrenta dificuldades no início do curso, mas que ao longo dele se molda e obtém o diploma, passa pelo processo de "assumir outro mundo", inclusive se identificando com esse mundo ao final do processo educacional.

Aqui não se está afirmando que o ensino da USP produz a superação das diferenças culturais, mas, por um processo institucional, essa Universidade substitui o mundo dos alunos, fazendo com que estes assumam as identificações da elite, especialmente no bacharelado, porque a ideia dos "altos estudos" ainda se mantém em detrimento de uma formação profissional, no caso das Ciências Sociais.

\section{CONCLUSÃO}

Vê-se que a intelligentsia (MANNHEIM, 2012) não abdicou de sua "capacidade de atuar de modo próprio", pois grande parte de suas forças de intervenção continua a agir em razão do próprio sistema de reprodução, na medida 
em que licenciandos ingressantes vêm sendo preparados da mesma maneira desde a criação da USP. É possível identificar esse processo na mudança do perfil docente.

\begin{abstract}
Durante muito tempo, no Brasil e em tantos outros países, o corpo discente das escolas foi constituído por alunos provenientes de estratos sociais pouco diferenciados. No Ensino Superior, havia até mesmo identidade de gênero, pois os alunos eram do sexo masculino. Por isso mesmo, o modelo predominante na educação no Brasil foi o da educação homogênea, que, aliás, sempre pareceu justo, pois esse modelo preconizava atender a todos os alunos de forma igual e equitativa. No entanto, com 0 processo de democratização (ou de massificação) do ensino, passaram a ter acesso à escola pessoas provenientes de outros estratos sociais, com interesses, motivações e heranças culturais diferentes e com competências e conhecimentos em diferentes graus de desenvolvimento. Esta situação tornou inviável a postura secular do professor de desenvolver sua atividade para um alunado típico (GIL, 2012, p. 40).
\end{abstract}

O corpo discente dos cursos de Ciências Sociais, nas primeiras décadas, não se diferenciava da descrição de Gil (2012). O curso foi criado para "atender a todos os alunos de forma igual e equitativa", no entanto, o perfil dos ingressantes foi se modificando ao longo do tempo. Tal mudança foi negligenciada, porque foram ignorados os estratos sociais e as heranças culturais que dificultam o processo educacional do estudante. Porém, aos olhos dos docentes, o esforço é condição suficiente para que o aluno atenda aos requisitos do ensino homogêneo. Nesse sentido, considerou-se:

Os estudantes universitários, por já possuírem uma "personalidade formada" e por saberem o que pretendem, não exigiriam de seus professores mais do que competência para transmitir os conhecimentos e para sanar suas dúvidas. Por essa razão é que até recentemente não se verificava preocupação explícita das autoridades educacionais com a preparação de professores para o Ensino Superior. Ou melhor, preocupação existia, mas com a preparação de pesquisadores, ficando subentendido que quanto melhor o pesquisador fosse mais competente professor seria (GIL, 2012, p. 1).

Para os docentes universitários, o termo "personalidade formada" designa

Inter-Legere - Revista de Pós Graduação em Ciências Sociais da UFRN

Natal RN, ISSN 1982-1662 no 18, jan./jun. de 2016 p. 150-167 
A FORMAÇÃO DO PROFESSOR DE SOCIOLOGIA DO ENSINO MÉDIO: UM ESTUDO SOBRE O CURSO DE CIÊNCIAS SOCIAIS DA UNIVERSIDADE DE SÃO PAULO Cassiana Tiemi Tedesco Takagi

alguém preparado para acompanhar o curso, independentemente de suas questões socioeconômicas. Quando Gil (2012) analisa que a preparação docente universitária resume-se ao seu desempenho enquanto pesquisador, o autor também questiona que esse princípio educacional é reproduzido nos cursos de formação de professores. A esse respeito, o autor acrescenta:

[...] no Ensino Superior é onde menos se verifica menor diversidade em relação às práticas didáticas. As aulas expositivas são as mais frequentes e o professor de modo geral aprende a ensinar por ensaio e erro. O professor constitui a principal fonte sistemática de informações, e uma das habilidades que mais incentiva nos alunos é a memorização. A prática mais constante de avaliação da aprendizagem consiste em aplicar provas e dar notas, que com frequência também é usada como meio de estabelecer autoridade em relação ao aluno. Aos alunos, por sua vez, cabe colocarem-se na condição de ouvintes e esperar que os professores "deem aulas" (GIL, 2012, p. 6).

Se "o professor de modo geral aprende a ensinar por ensaio e erro", essa condição é reproduzida nos cursos e, de alguma maneira, a ênfase da docência recai sobre a prática. Se a evidência está na prática, pouco se problematiza a seu respeito e grande parte dos textos de formação se caracteriza pelo tom prescritivo:

Não basta reconhecer as dificuldades de aprendizagem de crianças e jovens que não atingiram os níveis esperados em determinadas atividades; é necessário que os ensinantes reconheçam como sua função elevar progressivamente esses níveis. Nessa perspectiva, o ensinar transforma-se em incentivar, instigar, provocar, talvez desafiar. Na verdade, ensinar algo é sempre desafiar o interlocutor a pensar sobre algo (CASTRO, 2012, p. 19).

Se ensinar é desafiar, cabe questionar de que maneira os licenciandos são desafiados nos cursos de formação, especialmente quando são orientados a "incentivar, instigar, provocar, talvez desafiar". Não se questiona a necessidade de reflexão, especialmente no que se refere às disciplinas:

Um projeto educacional pressupõe, portanto, tanto o aspecto investigativo da Didática, identificando o que a vivência e as pesquisas atuais revelam a respeito da escola e do ensino, quanto 0 
prescritivo, que considera uma utopia: a escola ideal. A utopia, transformada em projeto, deixa o espaço do sonho e começa a influir na realidade. Mas, no caso da escola, é fundamental que o projeto pedagógico seja pensado e construído de forma coletiva (não só pelos profissionais, como também pelos funcionários, alunos, seus pais e outras pessoas significativas da comunidade) (PENIN, 2012, p. 34).

Penin (2012) alerta para o caráter prescritivo da disciplina Didática, que concebe "a escola ideal" e, de alguma forma, "um professor ideal", quando prescreve ações práticas, retirando dele o caráter reflexivo, usualmente o caráter investigativo, indicado pela autora ao se referir à pesquisa e raramente à ação docente. Apesar de a autora discorrer sobre uma "utopia: a escola ideal", ela prescreve a necessidade de o projeto pedagógico ser coletivo, de modo que essa ideia de mobilizar toda uma comunidade é de alguma forma prescritiva e utópica.

Se, em Penin, a questão prescritiva surge de maneira mais escamoteada, em outros autores, ela é mais evidente.

O que temos que acrescentar é que o professor precisa também construir o saber fazer em relação a esses saberes e que o locus para obtenção de dados que potencializam a relação teoria - prática é, ainda, a escola. Atividades de estágio direcionadas para essa análise crítica da escola e de seu interesse devem fazer parte da formação de todos os professores (CARVALHO; PEREZ, 2012, p. 115).

Desse modo, a postura crítica do licenciado está imersa em um protocolo, no qual ele deve estabelecer uma relação teoria-prática no estágio, construindo assim uma postura crítica. Essa questão restringe-se à prescrição quando pouco se problematiza a formação docente e as demais questões presentes na escola, especialmente quando o licenciando se coloca como futuro docente e não como pesquisador da escola.

Nesse sentido, observou-se nos dados analisados que o currículo dos alunos de Ciências Sociais oferece mais um molde estudantil do que uma problematização da profissão docente, pois

Importa-se mais aqui, para nossas considerações, o fato do indivíduo 
A FORMAÇÃO DO PROFESSOR DE SOCIOLOGIA DO ENSINO MÉDIO: UM ESTUDO SOBRE O CURSO DE CIÊNCIAS SOCIAIS DA UNIVERSIDADE DE SÃO PAULO Cassiana Tiemi Tedesco Takagi

não somente absorver os papéis e atitudes dos outros, mas nesse mesmo processo assumir o mundo deles. De fato, a identidade é objetivamente definida como localização em um certo mundo e só pode ser subjetivamente apropriada juntamente com este mundo. Dito de outra maneira, todas as identificações realizam-se em horizontes que implicam um mundo social específico (BERGER; LUCKMANN, 2012, p. 171).

O processo educacional vivido no curso produz tamanha adequação social que, ao ingressar, o aluno vive momentos de conflito, especialmente pelas dificuldades de acompanhá-lo, mas, ao longo do curso, ele assume que o conhecimento é mais relevante do que o exercício profissional. O licenciando acaba por assumir "papéis e atitudes dos outros", ou seja, ele concorda com o projeto da intelligentsia de que os "altos estudos" definem o sociólogo, mas nem sempre coordena esse papel com o de docente. Além disso, com o parco tempo destinado à licenciatura, por causa do número reduzido de disciplinas desta e do excessivo número do bacharelado, não consegue problematizar a docência em Ciências Sociais para dialogar com a formação do bacharel. Ao final, o licenciado em Ciências Sociais assume como seu o mundo das elites, de acordo com as intenções reveladas no currículo, e o mais preocupante: é possível que ele reproduza essa concepção na educação básica.

\section{REFERÊNCIAS}

ALMEIDA, W. M. USP para todos? Estudantes com desvantagens socioeconômicas e educacionais e fruição da universidade pública. São Paulo: Musa, 2009. 208p.

BAILLAUQUÉS, S. Trabalho das representações na formação dos professores. In: PAQUAY, L. et al. Formando professores profissionais: quais estratégias? quais competências? Porto Alegre/RS: Artmed, 2001. p. 37-54.

BERGER, P. L.; LUCKMANN, T. A construção social da realidade. Petrópolis: Vozes, 2012. 239p.

BURAS, K. L.; APPLE, M. W. Currículo, poder e lutas educacionais: com a palavra, os subalternos. Porto Alegre: Artmed, 2008. 296p.

CARVALHO, A. M.; PEREZ, D. G. O saber e o saber fazer dos professores. In: 
A FORMAÇÂO DO PROFESSOR DE SOCIOLOGIA DO ENSINO MÉDIO: UM ESTUDO SOBRE O CURSO DE CIÊNCIAS SOCIAIS DA UNIVERSIDADE DE SÃO PAULO

Cassiana Tiemi Tedesco Takagi

CASTRO, A. D.; CARVALHO, A. M. Ensinar a ensinar: didática para a escola fundamental e média. São Paulo: Cengage Learning, 2012. p. 107-124.

CASTRO, A. D. O ensino: objeto de Didática. In: CASTRO, A. D.; CARVALHO, A. M. Ensinar a ensinar: didática para a escola fundamental e média. São Paulo: Cengage Learning, 2012. p. 13-31.

CATANI, A.; NOGUEIRA, M. A. (Org.). Pierre Bourdieu: escritos de educação. Petrópolis: Vozes, 2008. 249p.

CORDEIRO, J. Didática. São Paulo: Contexto, 2012. 189p.

CUNHA, M. I. Inovações pedagógicas: o desafio da reconfiguração de saberes na docência universitária. In: PIMENTA, S. G; ALMEIDA, M. I. Pedagogia universitária. São Paulo: Editora da Universidade de São Paulo, 2009. p. 211-236.

GIL, A. C. Didática do ensino superior. São Paulo: Atlas, 2012. 283p.

GOODSON, I. F. O currículo em mudança: estudos na construção social do currículo. Porto: Porto, 2001. 231p.

LÉVI-STRAUSS, C. Tristes trópicos. São Paulo: Companhia das Letras, 1996. 400p.

MANNHEIM, K. Sociologia da cultura. São Paulo: Perspectiva, 2012. 208p.

NUNES, E. O. Educação superior no Brasil: estudos, debates, controvérsias. Rio de Janeiro: Garamond, 2012. 592p.

PAVÃO, A. Universidade e setores populares: identidades, motivações, projetos e sociabilidades. In: DAUSTER, T. (Org.). Antropologia e educação. Rio de Janeiro: Forma \& Ação, 2007. p. 59-86.

PENIN, S. T. de S. Didática e Cultura: o ensino comprometido com o social e a contemporaneidade. In: CASTRO, A. D.; CARVALHO, A. M. Ensinar a ensinar: didática para a escola fundamental e média. São Paulo: Cengage Learning, 2012. p. 33-52.

SAVIANI, D. Problemas e perspectivas da universidade pública brasileira hoje. In: SHEEN, M. R. (Org.). Recortes da história de uma universidade pública: o caso da Universidade Estadual de Maringá. Maringá: Eduem, 2001. p. 329-338. 